\title{
Viabilidade econômico-financeira de filmes brasileiros
}

\author{
Liana Ribeiro dos Santos ${ }^{1}$ \\ Paulo Vitor Jordão da Gama Silva² \\ Phillip Cattley ${ }^{3}$
}

\footnotetext{
${ }^{1}$ Doutora em Administração - Finanças - IAG/PUC-Rio (2013). Mestre em Administração - Instituto Coppead de Administração / UFRJ (2008). Pós-Graduada em Ciências Contábeis - EPGE-FGV- RJ (1998). Bacharel em Matemática, modalidade Informática - UERJ (1985). Professora de Finanças do departamento de Administração (IAG) da Pontifícia Universidade Católica do Rio de Janeiro PUC-Rio.

e-mail: liana.ribeiro@prof.iag.puc-rio.br

2 Graduado em Administração (PUC-RIO) e Contabilidade (UNESA), também possui mestrado em finanças pela PUC-RIO. Possui experiência profissional em empresas públicas, privadas e multinacionais, atuando em áreas como: planejamento e controle financeiro, controladoria, contabilidade e projetos financeiros. Atualmente é doutorando em finanças pela PUC-RIO, sóciodiretor da empresa Blockchain Finance (com foco em cursos de criptomoedas e projetos de consultoria) e membro do grupo de pesquisa CNPq de finanças comportamentais da PUC-RIO. e-mail: rjdagama@hotmail.com

${ }^{3}$ Graduado em Administração com ênfase em finanças pela PUC-RIO. 


\section{Resumo}

Filmes sempre foram considerados não somente um meio de entretenimento popular, mas também, em alguns casos, ótimos meios de investimento. Não obstante o retorno invejável de certas produções, alguns investidores desconsideram filmes - quase que automaticamente - quando estão à procura de um bom e rentável investimento. Seriam filmes brasileiros investimentos arriscados, inacessíveis ou, por quaisquer razões, desinteressantes? Teriam os investidores as informações necessárias para alocar seus recursos em filmes brasileiros com confiança? Vale a pena investir na indústria cinematográfica nacional? Este estudo teve por objetivo responder a essas perguntas, bem como desmistificar o cinema no Brasil como forma de investimento ao analisar uma amostra de três filmes com orçamento limitado a UUS $\$ 2.190 .000$ (considerando a média orçamentaria de filmes nacionais de $\mathrm{R} \$ 7.000 .000$ ). Foi possível observar que investir em filmes nacionais pode ser não somente viável, mas também rentável.

Palavras-chave: filmes brasileiros; investimento; rentabilidade; ANCINE.

\section{Abstract}

Movies have always been regarded as not just a popular way of entertainment, but also, in some cases, great means of investment. Despite the enviable return of some productions, a number of investors seem to disregard movies almost automatically when they are looking for a good and profitable investment. Are Brazilian movies risky investments, inaccessible or, for any reason, uninteresting? Would investors have the information they needed to confidently allocate their resources in Brazilian movies? Is it worth investing in the national movie industry? This study aimed to answer these questions, as well as to demystify movies in Brazil as a form of investment when analyzing a sample of three movies with a budget limited to UUS\$2.190.000 (considering the average budget of national movies of $R \$ 7.000 .000$ ). It was possible to observe that investing in national movies can be not only viable but also profitable.

Keywords: Brazilian Movies, Investment, Profitability, ANCINE, Incentives. 


\section{Introdução}

O Brasil encontra-se em crise. Porém, nem todas as indústrias foram afetadas pela crise política e econômica do país. Tendo como exemplo a indústria do cinema, que, segundo o G1 (2017), bateu recordes com 143 filmes lançados e mais de 184 milhões de ingressos vendidos, em 2016, 188 salas de cinema foram construídas, somando-se às 3.168 salas já em funcionamento, marcando um forte contraste com a produção industrial do país, que teve queda de $6,6 \%$ no ano (HESSEL, 2017).

A título de exemplo, o filme brasileiro Os dez mandamentos: o filme (Alexandre Avancini, 2016) obteve o maior público do cinema nacional, com mais de 11 milhões de ingressos vendidos (MELO, 2016), enquanto Aquarius (Kleber Mendonça Filho, 2016), outra produção brasileira, de escala significativamente menor, concorreu à Palma de Ouro no Festival de Cannes, dentre outros prêmios. Ressalta-se, por oportuno, que Aquarius foi orçado em $\mathrm{R} \$ 3.400 .000,00$ e, até o final de 2016, já havia retornado aos seus investidores todo o capital investido.

Por que, então, protegidos da crise, com indústria em crescimento e produções promissoras e rentáveis, filmes são descartados como forma de investimento? A verdade é que pouco é conhecido a respeito dos filmes como forma de investimento. Um investidor experiente poderia especular com certa confiança os principais custos de diversos empreendimentos, ou as margens de lucro de diversos setores, porém, entenderia ele os principais custos envolvidos em produções de filmes, ou saberia o retorno que pode esperar?

Tendo em vista responder aos questionamentos levantados, o objetivo deste estudo é verificar a viabilidade econômico-financeira de filmes brasileiros (o orçamento dos filmes pesquisados foi limitado a US\$2.190.000, entendendo que a média orçamentaria de filmes nacionais é de $\mathrm{R} \$ 7.000 .000)$. Os investidores precisam de informações para comparar os filmes com outros meios de investimento e, com base nos dados, escolher como aplicar seu capital do melhor modo possível. As fontes de receita e os principais custos inerentes às produções cinematográficas serão abordados, visto que, com base nos custos, o investidor poderá comparar projetos, bem como identificar possíveis riscos na produção. Indicadores financeiros como VPL (Valor Presente Líquido), TIR (Taxa Interna de Retorno) e payback (tempo de retorno), usados para determinar a atratividade de investimentos, também serão estudados, permitindo assim um melhor entendimento da rentabilidade de filmes em relação a investimentos em projetos de outros setores. Os principais riscos relacionados a investimentos em filmes também serão avaliados, visto que são particulares ao meio e fundamentais para a tomada de decisão do investidor.

No que diz respeito à relevância acadêmica, demonstrar a viabilidade econômica de filmes brasileiros e divulgar os resultados poderá fomentar um maior 
debate sobre o tema no ambiente acadêmico, trazendo mais informações de qualidade para alunos de administração e cinema, ou qualquer um que se interesse pelo tópico. Quanto ao investidor, o estudo visa informa-lo para que possa considerar filmes como forma de investimento e, consequentemente, aproveitar o crescimento de uma indústria em constante ascensão. Produtores de filmes nem sempre podem contar com apoio do governo para financiamento, contudo, se houver uma maior divulgação do seu índice de lucratividade, órgãos governamentais (e entes privados) terão maior interesse em investir no ramo, o que poderá resultar em um aumento do número de produções nacionais.

\section{Referencial teórico}

\subsection{Etapas e custos da produção de filmes}

Segundo Salles (2008), existem três etapas básicas no processo de produção de um filme, que são: pré-produção, produção e pós-produção. A primeira etapa inicia-se após a captação de recursos, e consiste em uma organização sistemática de como serão conduzidas as filmagens. A segunda etapa é aquela na qual o processo de filmagem começa e todas as pessoas envolvidas no projeto prestam apoio ao diretor. A terceira etapa consiste na desmontagem do set de filmagem e na finalização do filme.

$\mathrm{Na}$ primeira etapa, é necessário elaborar um cronograma para o projeto, bem como verificar a disponibilidade da equipe, atores, locações e quaisquer equipamentos, sejam eles técnicos ou artísticos, que precisarão ser usados ao longo da filmagem (COLLUSSO, 2009). A aquisição dos direitos de um argumento (roteiro) ou sua elaboração também precisam ser concluídas, e todas as permissões para o processo de filmagem devem ser obtidas. Em suma, é um processo de organização de grande importância, que precisa ser definido e gerenciado para evitar desperdício de tempo e capital ou problemas que podem ameaçar a continuidade do filme.

A segunda etapa, como dito anteriormente, é a de produção, na qual o processo de filmagem começa, e na qual todas as pessoas envolvidas no projeto, sejam atores, roteiristas, iluminadores, figurinistas, técnicos de som e imagem, filmadores, dentre inúmeras outras funções, prestam apoio ao diretor. Em outras palavras:

(...) cabe ao departamento de produção ter certeza de que cada membro da equipe, cada cenário, cada objeto de cena, cada equipamento, cada peça de vestuário está em seu devido lugar, a ser utilizado pelo diretor quando necessário em cada fase da produção, no contexto de prazos e orçamentos. (RODRIGUES, 2007: 68)

A terceira e última etapa da produção de um filme é a pós-produção, que 
consiste em duas importantes etapas: a desmontagem do set de filmagem e a finalização do filme (SALLES, 2008). Para desmontar um set, todos os equipamentos eletrônicos, incluindo câmeras e microfones, precisam ser desinstalados e removidos. Roupas e props de filmagem devem ser retirados e, caso alugados, devolvidos. Construções de cenário devem ser desmontadas, e o que foi emprestado deve ser retornado ao seu devido lugar. Contratos firmados com atores e equipes também precisam ser encerrados e as respectivas partes, pagas (SALLES, 2008). Quanto à finalização do filme, o arranjo da música precisa ser inserido e as várias cenas, editadas, sendo os efeitos especiais inseridos. Após a etapa de pós-produção, um filme segue para distribuição em cinemas, festivais, serviços on demand (Net Now, AppleTV, Netflix, GooglePlay), DVDs e Blu-Ray, mediante contratos assinados com as partes. Custos de divulgação, campanhas publicitárias e eventos estarão presentes nessa etapa.

Dentro de uma estrutura de custo, notam-se os conceitos de custo fixo e custo variável. O Serviço Brasileiro de Apoio às Micro e Pequenas Empresas, SEBRAE, define custos fixos como sendo "gastos que permanecem constantes, independente de aumentos ou diminuições na quantidade produzida e vendida" (SEBRAE, 2016), enquanto custos variáveis são "aqueles que variam diretamente com a quantidade produzida ou vendida, na mesma proporção" (SEBRAE, 2016).

Uma estrutura de custo vai além de identificar os tipos de custos e a proporção entre fixos e variáveis presentes em um projeto. Uma estrutura pode ser examinada de forma mais específica, como por exemplo: custos por produto, por serviço, por cliente e por região geográfica, permitindo o escrutínio e análise de cada categoria e como esta impacta o negócio como um todo. Entender onde incidem os maiores gastos pode ser o primeiro passo para reduzi-los.

Os custos para pré-produção, produção e pós-produção de um filme podem ser consideráveis (ver Tabela 1). Esses custos incluem escritores, atores, diretores, produtores, compositores e músicos, efeitos visuais, cenários, dublês, aluguel de câmeras e microfones, construção de set, aluguel de vestuário, entre outros. O gasto total para cada um desses fatores irá variar em função do tamanho e do tipo de filme, bem como do lugar em que incidem os custos. Um investidor potencial pode se utilizar de comparações entre tipos de custos de diferentes filmes, identificando discrepâncias entre custos ou oportunidades. Abaixo segue uma tabela com os principais gastos de cada etapa da produção de um filme. 


\begin{tabular}{|l|l|l|}
\hline \multicolumn{1}{c|}{ Pré-produção } & Produção & Pós-produção \\
\hline Aquisição do roteiro & Diretor & Edição do filme \\
Pesquisa de locações & Roteirista & Trilha sonora \\
Design de figurino & Atores & Titulos e créditos \\
Seleção da equipe técnica & Produtores & Dublagens \\
Seleção de elenco & Cameraman & Efeitos especiais \\
Design do set & Assistente de câmera & Desmontagem do \\
Desenvolvimento do script & Técnicos de som & \\
Pesquisa & Técnicos de imagem & \\
Seguros & Figurinista & \\
Custos de viagem & Equipe de construção do & \\
Permissões de filmagem & set & \\
Pagamento de locações & Gerente de produção & \\
& Equipamento de câmera & \\
& Equipamento de som & \\
& Equipamento de luz & \\
\hline
\end{tabular}

Tabela 1: Gastos em filmes, por etapa. Fonte: ANCINE (2017).

\subsection{Fontes de financiamento e incentivos fiscais nacionais}

Empresas podem utilizar capital próprio ou de terceiros para o financiamento de projetos. As fontes de financiamento variam, e incluem: aumento do capital social, empréstimos bancários, desinvestimento de ativos, crédito de fornecedores, aluguel de ativos, recursos do sistema financeiro, leasing de ativos, venture capital, programas de incentivo do governo, crowdfunding, entre demais alternativas.

Para um projeto de filme, os produtores podem pegar empréstimos bancários, venture capital ou usar capital próprio. Alternativamente, podem usufruir de programas de incentivo do governo como o PRODECINE (FSA, 2017), da Agência Nacional de Cinema (ANCINE), bem como recorrer a incentivos fiscais, através da Lei do Audiovisual ou da Lei Rouanet, ou até mesmo utilizar métodos como crowdfunding e product placement para arrecadar recursos.

Por último, projetos cinematográficos bem-sucedidos estão aptos a serem qualificados para o PAR ou PAQ. O PAR, Prêmio Adicional de Renda, é um investimento direto realizado anualmente pela ANCINE com o objetivo de estimular um maior diálogo da cinematografia nacional com o seu público. Contempla empresas produtoras, distribuidoras e exibidoras de filmes de longa-metragem. Através do incentivo, produtoras de filmes que obtiveram sucesso de bilheteria 
recebem recursos adicionais para serem investidos exclusivamente no desenvolvimento de projetos, em complementação de recursos para filmagem ou na finalização. Os valores concedidos pelo prêmio variam de acordo com o número de ingressos vendidos.

O PAQ, ou Programa ANCINE de Incentivo à Qualidade do Cinema Brasileiro, é também um prêmio concedido a projetos cinematográficos de sucesso. Diferentemente do PAR, cujo critério de premiação é o sucesso na bilheteria, o PAQ busca incentivar projetos que obtiveram reconhecimento por suas qualidades técnicas e artísticas. A agência então premia projetos de acordo com o sucesso obtido através de honrarias e prêmios no circuito de festivais de cinema. Os valores concedidos em prêmios são fixados anualmente, sendo distribuídos de forma igualitária entre as empresas produtoras beneficiadas, e precisam necessariamente ser utilizados na produção de novos filmes.

Existem dois tipos de incentivos fiscais concedidos para filmes, o fomento direto e o fomento indireto. Fomento direto consiste em "apoio financeiro à produção com recursos orçamentários próprios, mediante seleção e concursos públicos elaborados com base na Lei de Licitações (8.666/93)" (FORNAZARI, 2006: 658). Já o fomento indireto consiste na "autorização e fiscalização dos projetos com recursos de renúncia fiscal, de acordo com as leis: Rouanet e Lei do Audiovisual" (FORNAZARI, 2006: 658).

A Lei Rouanet é um mecanismo de incentivo fiscal que permite que contribuintes possam abater até $4 \%$ de seu imposto de renda, no caso de pessoa jurídica, e 6\%, no caso de pessoa física (QUERO INCENTIVAR, 2017a), para fins de doação ou para o patrocínio de projetos culturais.

No que diz respeito à Lei do Audiovisual, existe mais de uma possibilidade. Uma empresa produtora pode emitir certificados de investimento de até $80 \%$ dos fundos requeridos para financiar uma produção, desde que o valor emitido não ultrapasse a ordem de $\mathrm{R} \$ 3.000 .000,00$ (ZAVERUCHA, 1996). Os certificados de investimento, por sua vez, permitem abater 100\% dos recursos despendidos, limitados a 4\% do IR (ZAVERUCHA, 1996), na compra de papéis de investimento, que auferem ao comprador o direito de exibição de sua marca, podendo também oferecer direitos de comercialização de obras e de projetos de distribuição, exibição e infraestrutura (QUERO INCENTIVAR, 2017b).

\subsection{Principais fontes de receita e riscos da indústria cinematográfica}

Existem várias fontes de receita disponíveis para filmes, sendo algumas dependentes do sucesso de outras. É importante que o investidor em filmes entenda o potencial dessas receitas quando contempla filmes como investimento. Pode-se citar a venda de ingressos de cinema como primeira fonte de receita de filmes. 
Nessa fonte, existe um acordo entre os produtores de filme e as empresas de exibição ou cinemas.

O valor acordado é baseado na venda de ingressos, e pode partir de uma quantia fixa ou, alternativamente, de um percentual. No que se refere ao percentual, existe variação, visto que filmes com grande demanda têm maior poder de barganha em relação a produções menores. Uma regra de mercado contempla que o exibidor retenha $50 \%$ do lucro de bilheteria de um filme, com os outros $50 \%$ sendo repassados ao distribuidor e ao produtor nas proporções de $30 \%$ e $70 \%$, respectivamente (STERNHEIM, 2013), auferindo ao último $37,5 \%$ dos lucros totais de bilheteria. Com termos acordados, o cinema ganha o direito de exibir um filme por um determinado período de tempo, sendo este, normalmente, de cinco anos.

Podem ser citadas também a venda de DVD/Blu-rays, bem como a venda dos direitos de exibição para streaming, como fontes de receita importantes para filmes. O mercado de DVDs no Brasil tem diminuído com o aumento de serviços on demand, sendo percebida uma retração de $22 \%$ no número de obras lançadas em DVD de 2015 para 2016 e um crescimento de $68 \%$ no número de serviços de vídeo por demanda entre os anos 2012 e 2016 (OCA, 2017). Não obstante a redução no número de DVDs vendidos e a clara preferência do brasileiro pelo mercado de streaming - a Netflix aumentou seu número de assinantes em mais de $87 \%$ de outubro de 2015 a setembro de 2016 (MEIO\&MENSAGEM, 2016) -, DVDs de filmes brasileiros têm apresentado um crescimento de $74 \%$ em lançamentos (OCA, 2017), mostrando uma maior atuação de produções brasileiras no mercado audiovisual e trazendo oportunidades para potenciais investidores.

Os direitos autorais de um filme, incluindo sua trama, personagens e todo seu universo fictício, podem ser alugados ou vendidos em acordos de merchandising. Assim, empresas fabricantes de produtos como camisetas, brinquedos, cadernos, canetas e livros, dentre outros, podem usufruir de uma produção de sucesso para aumentar a divulgação e venda de seus produtos.

Também é importante citar como fonte de receita o product placement, que consiste "na inserção de uma marca ou produto dentro de um programa" (LAFUENTE; ZANONI; ALMEIDA, 2016), e visa um aumento da divulgação e da popularidade do produto, resultando em maiores vendas. É possível notar claros exemplos desta técnica em filmes que divulgam marcas de refrigerantes, restaurantes, carros e eletrônicos, dentre outros. O product placement no Brasil é normalmente responsável por 10 a $20 \%$ do orçamento de produções que trabalham com essa técnica. Nos Estados Unidos, o percentual é significativamente maior (ARBEX, 2007: 65).

Todo investimento tem riscos (FINRA, 2017), sendo estes ampliados pela falta de conhecimento do investidor (SNYDER, 2017). Entretanto, existem alguns riscos inerentes ao investimento em filmes que não estão necessariamente 
presentes em outros projetos. É importante que o investidor considere todos eles antes de escolher onde alocar seus recursos.

Um filme pode ser composto de um grande elenco, com renomados atores, produtores, compositores e diretor, porém a participação destes em uma produção não é garantia de que a mesma terá sucesso de bilheteria (REILLY; CUNNINGHAM, 2015). A subjetividade da apreciação e a variabilidade de gostos também podem contribuir para o fracasso de uma produção, visto que tendências que antes faziam sucesso eventualmente não terão o mesmo apelo.

O tempo de produção de um filme varia de acordo com um grande número de fatores, incluindo o gênero e o tamanho do projeto. No processo de préprodução, quando um cronograma é elaborado, produtores podem prever a maioria dos fatores e planejar contingências para evitar que problemas impeçam o processo de filmagem. Todavia, existem alguns fatores que não podem ser previstos com grande certeza, tornando o processo de filmagem potencialmente arriscado e mais custoso. O clima, inconsistente, pode fazer com que a filmagem seja suspensa enquanto as condições de tempo sejam adversas. Condições ruins de tempo também contribuem para que os salários de horistas aumentem, bem como os custos de locação, transporte, alimentação, dentre outros. Qualquer dano feito a equipamentos durante viagens também precisa ser considerado, visto que muitos filmes utilizam câmeras e microfones alugados de custo elevado.

Uma pesquisa realizada pela empresa de software Mark Monitor constatou que o Brasil é o quarto país que mais pirateia filmes na internet (OLHAR DIGITAL, 2014), prejudicando a indústria e tornando a viabilidade de projetos de filmes ainda mais incerta.

\section{Metodologia e base de dados}

O processo de investigação foi realizado em duas principais etapas: (I) coleta de dados do mercado audiovisual, incluindo mecanismos de incentivo e custos, além das práticas da indústria que determinam a divisão de lucro entre os sócios de um projeto cinematográfico; (II) análise de dados específicos de projetos, incluindo orçamentos, receitas de bilheteria, patrocínios, investimentos e impostos.

Na primeira etapa, a coleta de dados de mercado foi realizada na ANCINE com a ajuda da Coordenação de Análise de Direitos. Um roteiro de entrevista informal foi preparado, com perguntas abertas que visavam situar o autor na indústria de filmes brasileira. Uma segunda entrevista, de caráter informal e sem roteiro definido, foi realizada com um profissional da indústria, para melhor entender o papel dos incentivos fiscais no processo de financiamento de filmes, bem como a função da distribuidora na indústria de filmes brasileiros.

A segunda etapa foi principalmente realizada através de livros, artigos 
acadêmicos e websites. A partir dos resultados, foi desenvolvido um estudo com indicadores financeiros para demonstrar a viabilidade dos projetos analisados de acordo com os critérios de VPL, TIR e payback (Equações 1, 2 e 3, respectivamente).

\section{Equação 1:}

$$
V P L=\sum_{t=0}^{n} \frac{F C_{t}}{(1+i)^{t}}
$$

Onde: FC é o fluxo de caixa do período em $t$ anos ou meses; $n$ é o tempo total do projeto (em anos ou meses); $i$ será a taxa de atratividade que o investidor estará utilizando para participar do projeto. Um valor positivo significa que a soma dos fluxos, descontada a taxa, é maior do que o investimento inicial, portanto, o projeto apresenta viabilidade para o investidor.

$$
\begin{gathered}
\text { Equação 2: } \\
V P L=\sum_{j=1}^{n} \frac{F C_{j}}{(1+T I R)^{n}}=0
\end{gathered}
$$

Onde: FC são os fluxos de caixa de ordem j; $\mathbf{n}$ é o período; o VPL é zero, pois a TIR demonstra a taxa de indiferença de investimento. Logo, se o investidor fizer uso de capital de terceiros, a taxa de custo de capital deve ser menor que a TIR, e se o investidor fizer uso de capital próprio, a TIR deve ser maior que a TMA (Taxa Mínima de Atratividade).

\section{Equação 3:}

Payback Descontado $=P_{T-1}+\frac{\text { Fluxo de Caixa Acumulado Ajustado } \text { A }_{T-1}}{\text { Fluxo de Caixa Ajustado }}$

Onde: é o período imediatamente anterior àquele no qual houve o primeiro Fluxo de Caixa Acumulado Ajustado positivo; é o fluxo imediatamente anterior ao primeiro fluxo de caixa acumulado positivo em módulo; é o primeiro fluxo de caixa ajustado (atualizado pela taxa de desconto) positivo da série.

O estudo tem como foco três produções cinematográficas nacionais: Aquarius, 2 Coelhos (Afonso Poyart, 2012) e O shaolin do sertão (Halder Gomes, 2016), de autores, produtores, diretores e elenco diferentes, escolhidas aleatoriamente, porém dentro de um padrão comum. O orçamento dos filmes 
pesquisados foi limitado a US $\$ 2.190 .000,00$, entendendo que a média orçamentaria de filmes nacionais é de $R \$ 7.000 .000,00$. Estas produções apresentam diferentes estruturas de capital, que podem ser compostas de capital majoritariamente incentivado, privado ou misto. Para obter os números utilizados na construção do modelo CAPM (Capital Asset Pricing Model), utilizado para definir o custo de capital do projeto, os websites da NYU/Damodaran e MarketWatch foram consultados.

O website BoxOfficeMojo, subsidiário da IMDB/Amazon, foi particularmente importante para obter informações relacionadas à bilheteria de filmes. O livro Film business: o negócio do cinema também foi de grande importância para o desenvolvimento do estudo.

É de importância para o leitor mencionar que existe confidencialidade acerca dos dados financeiros de produções cinematográficas nacionais, tendo em vista seu valor estratégico para produtoras, distribuidoras e exibidoras. Informações como o mês de captação de recursos ou o percentual de lucro auferido ao produtor em suas negociações com o distribuidor e exibidor não puderam ser obtidas, portanto foram estimadas.

O mês de captação de recursos apresentado, necessário para cálculos financeiros, é o mês prévio ao começo das filmagens. Neste trabalho, é estimado que existe valor do dinheiro ao longo do tempo, e que investidores evitam deixar seu capital fora de aplicações rentáveis e preferem alocar seus recursos somente no momento necessário, para maximizar seu lucro.

Lucros obtidos pela venda de unidades de DVD/Blu-Ray, bem como lucros provenientes de contratos de exibição para TV e serviços on demand não foram incluídos no estudo por motivo de inacessibilidade dos dados. Não obstante, para o investidor, é importante entender que essas fontes de lucro, embora secundárias, aumentam o VPL/TIR dos projetos e diminuem o payback descontado, tornando-os mais atrativos.

Incentivos fiscais, culturais, etc. foram incluídos quando disponíveis. Percentuais e prazos negociados entre a produtora e financiadores através de certificados de investimento para o filme $O$ shaolin do sertão não puderam ser obtidos, porém é importante lembrar que filmes que optam por captar financiamento na forma de certificados de investimento distribuem um percentual de seus lucros para investidores ao longo de um prazo negociado. Por esse motivo, o VPL e o TIR desses projetos podem sofrer alterações (BANESTES, 2015).

A taxa de desconto dos projetos, baseada na CAPM, foi convertida de anual para mensal com a finalidade de oferecer um resultado mais preciso da rentabilidade dos projetos em questão. Os valores dos orçamentos, receitas e patrocínios foram calculados a partir das taxas de câmbio dos respectivos períodos. Finalmente, 5\% de ISS (Imposto Sobre Serviços) foram calculados para cada projeto estudado (BARBOSA, 2017: 173). 


\section{Resultados}

Os três projetos estudados, embora de tamanhos semelhantes, apresentaram resultados distintos em função de particularidades de investimento e incentivo. Dessa forma, optou-se por apresentar e discutir os resultados separadamente para facilitar o entendimento e ampliar a análise individual de cada produção, com o intuito de esclarecer da melhor maneira possível como a viabilidade de cada um impacta na decisão de fazer o investimento (nacional ou internacional).

\subsection{Filme: Aquarius}

O premiado filme Aquarius teve o menor orçamento dos projetos estudados (ver Tabela 2). No que se diz respeito à composição do orçamento, pode-se dizer que o filme foi inteiramente financiado por capital incentivado, via Lei do Audiovisual, e por patrocínio cultural, via BNDES (Banco Nacional de Desenvolvimentto). Os produtores/investidores, no caso, obtiveram estimados $37,5 \%$ da receita de bilheteria do filme, além das participações negociadas para DVD/Blu-ray. O filme obteve um fluxo descontado de bilheteria de US\$1.887.991,76, com impostos de $5 \%$ descontados no cálculo.

Apresentou um VPL positivo, de US\$672.597,06. Por ser um projeto de financiamento patrocinado, não apresentou uma taxa interna de retorno, e o período de payback descontado pode ser considerado zero. Porém, uma simulação foi feita com investimento simbólico, gerando um valor expressivo de TIR. 


\begin{tabular}{|c|c|}
\hline DADOS DO PROJETO & \\
\hline FILME & Aquarius \\
\hline Ano de Lançamento & 2016 \\
\hline ORÇAMENTO EM US\$ & US\$1.011.194,76 \\
\hline Ano/Mês de Captação de Recursos & $\mathrm{jul} / 15$ \\
\hline \multicolumn{2}{|l|}{ INCENTIVOS } \\
\hline Lei do Audiovisual & US $\$ 580.357,14$ \\
\hline Patrocinio Cultural BNDES & US $\$ 431.547,62$ \\
\hline TOTAL & US\$1.011.904,76 \\
\hline \multicolumn{2}{|l|}{ PRODUTOR/INVESTIDOR } \\
\hline Investimento & $\mathrm{US} \$ 0,00$ \\
\hline Participação Estimada da Produção & $37,50 \%$ \\
\hline Participação Produt or/Investidor & US $\$ 672.597,06$ \\
\hline \multicolumn{2}{|l|}{ DADOS CAPM } \\
\hline $\mathrm{RF}(10$ Year $T$-Bill $)$ & $2,39 \%$ \\
\hline Emerging Morket Entertainment Beta & 1.12 \\
\hline Equity Risk Premium Brozil & $9,64 \%$ \\
\hline Country Risk Premium Brazil & $3,95 \%$ \\
\hline CAPM & $17,14 \%$ \\
\hline Taxa Mensal & $1,33 \%$ \\
\hline \multicolumn{2}{|l|}{ RESULTADOS } \\
\hline FLUXO DESCONTADO TOTAL & US\$1.887.991,76 \\
\hline IMPOSTOS (ISS) & US\$94.399,59 \\
\hline TOTAL & US\$1.793.592,17 \\
\hline VPL & US\$672.597,06 \\
\hline TIR & $\mathrm{N} / \mathrm{A}$ \\
\hline Payback descontado & 0 \\
\hline
\end{tabular}

Tabela 2: Resultados do filme Aquarius. Fonte: Desenvolvida pelos autores.

Aquarius representa, provavelmente, um dos melhores cenários que um investidor/produtor de filmes pode esperar. Seu orçamento foi de menos da metade da média de filmes produzidos hoje ( $R \$ 3,4$ milhões comparados a $R \$ 7$ milhões), e seu sucesso foi internacional, tendo conquistado 40 prêmios mundo afora. Exibido em 12 países, sua bilheteria teve um fluxo descontado total, após o pagamento de impostos, $87 \%$ superior a seu orçamento. Não obstante o sucesso acima relatado, que não inclui o cálculo das vendas de unidades de DVD/Blu-ray, da venda para serviços on demand ou os prêmios de incentivo concedidos pela ANCINE (PAR e $P A Q)$, o maior atrativo para o possível investidor ou produtor é outro. O projeto foi feito exclusivamente com recursos incentivados.

Para o investidor, é importante obter "capital barato", ou capital com juros baixos, para aumentar a rentabilidade do investimento. O capital incentivado, no entanto, diminui o risco consideravelmente, e pode, em alguns casos, anulá-lo. $\mathrm{O}$ 
investidor/produtor, então, é alavancado e protegido de risco, sendo sua taxa interna de retorno aumentada consideravelmente. No exemplo de Aquarius, um valor simbólico de US\$1 investido obteve uma TIR de $7.842 .612 \%$ e um VPL positivo de US $\$ 672.597,06$. Os produtores tiveram um período de payback descontado igual a zero, visto que nenhum recurso foi aplicado. Para investigar o impacto que a fonte de financiamento teve na rentabilidade de Aquarius, foi simulado um cenário no qual o orçamento incentivado foi substituído por capital próprio.

Os resultados apresentaram grande diferença de rentabilidade. O VPL, antes positivo, passou para -US\$339.307,70, enquanto a TIR, também negativa, ficou em $-11,1 \%$. Foi calculado que, caso o investidor quisesse obter um retorno igual ou superior à taxa de $17,14 \%$ (TMA do projeto), não poderia investir um valor superior a US $\$ 709.000,00$ (aproximadamente $70 \%$ do valor total de orçamento). Não obstante o segundo cenário, nota-se que o projeto original foi bem-sucedido, atendendo bem aos resultados de VPL, TIR e payback descontado.

\subsection{Filme: 2 Coelhos}

O filme de ação 2 Coelhos teve orçamento de US\$1.966.292,13 (ver Tabela 3). O produtor teve dificuldade em arrecadar fundos em curto prazo, e, por isso, optou por investir $80 \%$ do capital requerido para o orçamento, recorrendo a leis de incentivo para arrecadar os $20 \%$ que faltavam. Os produtores/investidores obtiveram estimados $37,5 \%$ da receita de bilheteria do filme, além das participações negociadas para DVD/Blu-ray.

Esse projeto apresentou um fluxo de bilheteria descontado de US\$1.511.399,55, já descontados os impostos. O VPL apresentado foi surpreendentemente negativo, de -US\$1.034.597,62, e a TIR ficou em $-24,33 \%$. Visto que não ocorre recuperação do investimento, não existe payback. Porém, é importante lembrar que o estudo não compreende fontes adicionais de receita, e que é possível que o filme 2 Coelhos tenha recuperado o capital investido através dessas fontes. 


\begin{tabular}{|c|c|}
\hline \multicolumn{2}{|l|}{ DADOS DO PROJETO } \\
\hline FILME & 2 Coelhos \\
\hline Ano de Lançamento & 2012 \\
\hline ORÇAMENTO EM UUS\$ & US\$1.966292.13 \\
\hline Ano/Mês de Captação de Recursos & set/09 \\
\hline INCENTIVOS & $\mathrm{R} \$ 393.258,43$ \\
\hline \multicolumn{2}{|l|}{ PRODUTOR/NVESTIDOR } \\
\hline Investimento & US\$1.573.033,71 \\
\hline Participação Estimada da Produção & $37,50 \%$ \\
\hline Participação Produtor/Investidor & US\$538.436 \\
\hline \multicolumn{2}{|l|}{ DADOS CAPM } \\
\hline RF (10 Year T-Bill) & $2,39 \%$ \\
\hline Emerging Market Entertainment Beta & 1.12 \\
\hline Equity Risk Premium Brazil & $9,64 \%$ \\
\hline Country Risk Premium Brazil & $3,95 \%$ \\
\hline CAPM & $17,14 \%$ \\
\hline Taxa Mensal & $1,33 \%$ \\
\hline \multicolumn{2}{|l|}{ RESULTADOS } \\
\hline FLUXO DESCONTADO TOTAL & US\$1.511.399,55 \\
\hline IMPOSTOS (ISS) & US $\$ 75.569,90$ \\
\hline TOTAL & US $\$ 1.435 .829,57$ \\
\hline VPL & US\$1.034.597,62 \\
\hline TIR & $-24,35 \%$ \\
\hline Payback descontado & 2 anos e 4 meses \\
\hline
\end{tabular}

Tabela 3: Resultados do filme 2 Coelhos. Fonte: Desenvolvida pelos autores.

O filme recebeu excelentes críticas (DIDIMO, 2012) e foi bem recebido pelo público brasileiro, que elogiou o estilo criativo do diretor, bem como as ousadas cenas de ação. Não obstante a boa recepção, o filme apresentou uma rentabilidade muito diferente da de Aquarius. Para começar, o filme não teve o mesmo impacto internacional, ficando sua receita com bilheteria restrita ao território nacional. A bilheteria nacional foi $11 \%$ maior do que o orçamento do filme, um número pouco expressivo, enquanto o fluxo descontado do projeto foi $27 \%$ menor do que o orçamento.

A produção pode ter obtido sucesso significativo com a venda de DVD/BluRays e dos direitos de exibição para canais de TV, porém, no que diz respeito à receita de bilheteria, não obteve grande sucesso. Em relação ao financiamento do filme, somente $20 \%$ do capital utilizado foi incentivado, tendo o produtor investido os outros $80 \%$ com capital próprio.

2 Coelhos não obteve bom resultado financeiro, com VPL negativo de -US\$1.034.597,62 e TIR de -24,33\%. Isso pode ser explicado na medida em que, de toda receita acumulada na bilheteria de um filme, somente $37,5 \%$ são destinados aos produtores, sendo grande parte retida pelo exibidor. Um filme como esse, que obteve receita razoável, precisaria de um sucesso muito maior de vendas para compensar os US $\$ 1.573 .033,71$ investidos pelo produtor. Com somente $20 \%$ de capital incentivado, os ganhos de bilheteria precisariam ser de no mínimo US $\$ 11.190 .000,00$ para obter-se um VPL positivo, uma receita que representa mais de cinco vezes a original, de US\$2.187.985,71.

Alternativamente, o projeto poderia ter aumentado o seu uso de capital 
incentivado. Ao investir não mais do que US $\$ 567.000,00$ (29\% do orçamento total), o investidor honraria a sua TMA de $17,14 \%$ e alcançaria um VPL positivo. O payback descontado do filme não foi atingido no cenário estudado, sendo estimado em mais de 2 anos e 4 meses. Porém, o cenário não contempla vendas de DVD/Blu-rays e receitas de direitos de exibição do produto, nem diferentes margens de negociação entre produtor/distribuidor/exibidor, que também podem ter um grande efeito no tempo que um projeto leva para retornar o que foi investido. Não obstante, no cenário estudado, o projeto não obteve o retorno financeiro esperado.

\subsection{Filme: $O$ shaolin do sertão}

A comédia/aventura $O$ shaolin do sertão teve o segundo maior orçamento dos três filmes estudados, com US\$1.818.181,82 (ver Tabela 4). O filme teve cerca de $60 \%$ de seu orçamento coberto por incentivos culturais, pelos quais empresas puderam, através da compra de certificados, exibir sua marca no filme. Os produtores/investidores obtiveram estimados $37,5 \%$ da receita de bilheteria do filme, além das participações negociadas para DVD/Blu-ray. O fluxo de bilheteria apresentado foi de US $\$ 2.321 .923,59$, descontados os $5 \%$ de ISS. O VPL foi positivo, a TIR foi de $25,38 \%$, e o payback descontado do filme foi de 2 anos e 4 meses.

\begin{tabular}{|c|c|}
\hline DADOS DO PROJETO & \\
\hline FILME & O shaolin do sertão \\
\hline Ano de Lançamento & 2016 \\
\hline ORÇAMENTO EM UUS\$ & US $\$ 1.818 .181,82$ \\
\hline Ano/Mês de Captação de Recursos & jun $/ 14$ \\
\hline \multicolumn{2}{|l|}{ INCENTIVOS } \\
\hline Incentivos Culturais (Lei 8.685/93) & US\$327.272,73 \\
\hline Incentivos Culturais (Artigo 3A) & US $\$ 750.000,00$ \\
\hline TOTAL & US $\$ 1.077 .272,73$ \\
\hline \multicolumn{2}{|l|}{ PRODUTOR/INVESTIDOR } \\
\hline Investimento & US\$740.909,09 \\
\hline Participação Estimada da Produção & $37,50 \%$ \\
\hline Participação Produtor/Investidor & US $\$ 827.185,28$ \\
\hline \multicolumn{2}{|l|}{ DADOS CAPM } \\
\hline $\mathrm{RF}(10$ Year T-Bill) & $2,39 \%$ \\
\hline Emerging Morket Entertainment Beta & 1.12 \\
\hline Equity Risk Premium Brozil & $9,64 \%$ \\
\hline Country Risk Premium Brazil & $3,95 \%$ \\
\hline CAPM & $17,14 \%$ \\
\hline Taxa Mensal & $1,33 \%$ \\
\hline \multicolumn{2}{|l|}{ RESULTADOS } \\
\hline FLUXO DESCONTADO TOTAL & US $\$ 2.321 .923,59$ \\
\hline IMPOSTOS (ISS) & US $\$ 116.096,18$ \\
\hline TOTAL & US $\$ 2.205 .827,41$ \\
\hline VPL & US $\$ 86.276,16$ \\
\hline $\mathrm{TIR}$ & $25,92 \%$ \\
\hline Payback descontado & 2 anos e 4 meses \\
\hline
\end{tabular}


O filme teve grande sucesso nacional, com mais de 500 mil espectadores em todo o país (ROCHA, 2016). Sua bilheteria superou o orçamento em $27 \%$. No que se diz respeito ao financiamento, o filme encontra-se exatamente entre Aquarius (que teve todo o seu orçamento incentivado) e 2 Coelhos (que contou com $20 \%$ de orçamento incentivado), tendo $60 \%$ de seu orçamento patrocinado (US $\$ 1.077 .272,73$ ). Obteve um VPL positivo de US $\$ 86.276,19$ e uma TIR acima da taxa mínima de atratividade $(25,38 \%)$.

O payback descontado foi de 2 anos e 5 meses, menor do que o de 2 Coelhos, porém significativamente maior do que o de Aquarius, tornando o investimento comparativamente longo. Para investigar o impacto que o financiamento incentivado tem na rentabilidade do projeto, é possível simular o financiamento do filme com $100 \%$ de capital próprio, obtendo um VPL negativo de -US\$990.996,54, e uma TIR de -14,06\%, novamente comprovando a importância da utilização de capital incentivado para a rentabilidade de filmes.

É importante lembrar que o projeto foi financiado em parte com certificados de investimento, e, portanto, precisará devolver dividendos aos seus financiadores. Porém, no presente cenário, pode se dizer que o filme $O$ shaolin do sertão foi bemsucedido no que diz respeito aos três indicadores (VPL, TIR e payback descontado) e apresenta viabilidade para o investidor.

\section{Conclusão}

Por meio deste estudo, foi possível observar que filmes brasileiros com orçamento limitado a UUS $\$ 2.190 .000,00$ (entendendo que a média orçamentaria de filmes nacionais é de $R \$ 7.000 .000,00$ ) podem ser não apenas viáveis, mas também extremamente rentáveis. Porém, como em qualquer projeto, existem riscos inerentes e medidas que precisam ser tomadas para minimizar o risco e aumentar a lucratividade do negócio.

Os três projetos de filmes estudados obtiveram receitas maiores do que seus orçamentos. Para se ter receita, é importante que exista qualidade percebida no produto ou serviço e ampla divulgação dessa qualidade. Quanto à receita, vale lembrar que, no Brasil, o produtor precisa dividir grande parte da bilheteria com o cinema (exibidor) e o distribuidor. $O$ processo de negociação entre o produtor e as demais partes é, portanto, muito importante para a maximização da receita e a viabilidade do projeto como um todo. Não foram contabilizadas outras receitas como comercialização para plataformas on demand, vendas de DVD/Blu-ray e product placement.

Não obstante o volume da receita, um filme não será viável caso apresente um custo que a exceda. Os custos que puderem ser controlados devem seguir o estabelecimento e cumprimento de um cronograma eficiente na etapa da pré- 
produção. Um cronograma eficiente compreende também uma utilização ótima de capital, ou seja, o capital do investidor não deve ficar fora de aplicações rentáveis, devendo ser requisitado somente quando necessário. É importante também apontar que um grande orçamento não necessariamente se traduz em maior receita, e que no estudo realizado com três filmes, o projeto de menor orçamento obteve o maior retorno (Aquarius).

Talvez um dos aspectos mais determinantes da viabilidade de um filme é o custo do capital. Como se notou na parte de análise dos resultados, é de interesse para o investidor obter capital com juros baixos para financiar seus projetos. Existe um valor máximo de capital próprio que pode ser aplicado a cada um dos três projetos sem que se comprometa o atingimento da TMA de 17,14\%. Para Aquarius, este valor é de $70 \%$ do orçamento; para 2 Coelhos, que obteve bilheteria significativamente menor, o valor é de $28 \%$ do orçamento; e para 0 shaolin do Sertão, o valor máximo é de $47 \%$ do orçamento. Através desta amostra, pode-se calcular uma média e constatar, com base nos resultados obtidos, que não mais de $49 \%$ de capital próprio deva ser utilizado para financiar projetos de filme (podendo uma estimativa mais conservadora sugerir $25 \%$ com base nos resultados de 2 Coelhos), preferindo-se sempre a utilização de capital incentivado, livre de risco e de obrigação de retorno.

Através de patrocínio, uma empresa pode, com recursos de incentivos, exibir sua marca em um filme. Para os produtores do filme, isto significa a detenção completa dos direitos comerciais da obra, o que eleva a rentabilidade do projeto como um todo. Adicionalmente, o risco do projeto cai à medida que patrocínios substituem o capital próprio, o que também apresenta uma grande vantagem para o investidor. Patrocínios podem advir de instituições privadas ou governamentais, como pelas leis Rouanet ou do Audiovisual, e representam o método menos custoso, logo, mais rentável (junto a prêmios de desempenho e product placement) de se produzir um filme.

Prêmios de desempenho, como PAQ e PAR, também são considerados excelentes opções para financiamento, visto que o capital premiado não precisa ser retornado para a agência emissora, sendo somente necessária sua aplicação em algum projeto. $O$ financiamento por product placement segue características semelhantes ao patrocínio, sendo considerado também um investimento em imagem por parte da marca. Difere do patrocínio no estilo de propaganda empregada, porém também não apresenta custos de juros para o projeto, nem requer a devolução do capital aplicado.

Como segunda preferência para a obtenção de capital, pode-se citar os certificados de investimento, que são vinculados a cotas de direitos de comercialização do filme. Embora estes reduzam o risco do projeto como um todo, demandam o pagamento de parcela dos lucros por parte do produtor. Este seria um 
tema interessante a ser abordado em estudos futuros, analisando a influência dos instrumentos de captação na composição dos filmes nacionais em comparação com grandes produções internacionais.

\section{Referências}

ANCINE. ANCINE lança edital do programa ANCINE de Incentivo à Qualidade - PAQ 2013. Rio de Janeiro, 2013. Disponível em: https://ancine.gov.br/pt-br/salaimprensa/noticias/ancine-lan-edital-do-programa-ancine-de-incentivo-qualidade-paq2013. Acesso em: 4 nov. 2017.

ANCINE. Carta de Serviços - Mecanismos de Fomento. Rio de Janeiro, 2017. Disponível em: https://cartadeservicos.ancine.gov.br/?pg=fomento. Acesso em: 31 out. 2017.

ANCINE. Fomento - PAQ. Rio de Janeiro, 2017. Disponível em: https://www.ancine.gov.br/fomento/paq. Acesso em: 4 nov. 2017.

ANCINE. Fomento - PAR. Rio de Janeiro, 2017. Disponível em: https://www.ancine.gov.br/sites/default/files/par/PAR\%202013\%20ANEXO_1A\%20cal culo\%20produtora.pdf. Acesso em: 4 nov. 2017.

ARBEX, A. L. M. Cinema e publicidade: um diálogo possível e necessário. 2007. Trabalho de Conclusão de Curso (Bacharel em Comunicação Social) - Departamento de Comunicação Social, Universidade Federal de Juiz de Fora, 2007. 65 p.

BANESTES. Certificado de Investimento Audiovisual. 2015. Disponível em: http://www.banestes.com.br/investimentos/invest_certificado_audiovisual.html.

Acesso em: 30 out. 2017.

BARBOSA, L. Film business: o negócio do cinema. Rio de Janeiro: Elsevier, 2017. p. 173.

WEBSITE - BOX OFFICE MOJO. Aquarius. Disponível em: http://www.boxofficemojo.com/movies/?page=intl\&id=aquarius.htm. Acesso em: 18 out. 2017.

WEBSITE - BOX OFFICE MOJO. O shaolin do sertão. Disponível em: http://www.boxofficemojo.com/movies/int//?page=\&country=BR\&id=_fOSHAO LINDOSERTO01. Acesso em: 18 out. 2017. 
WEBSITE - STERN - NYU. Country Default Spread and Risk Premiums. Disponível em: http://pages.stern.nyu.edu/ adamodar/New_Home_Page/datafile /ctryprem.html. Acesso em: 22 out. 2017.

COLLUSSO, L. C. O produtor e o processo de produção de filmes no Brasil. X Congresso de Ciências da Comunicação da Região Sul - Blumenau. Intercom Sociedade Brasileira de Estudos Interdisciplinares da Comunicação, 2009.

DIDIMO, D. 2 Coelhos (2012): ousadia e diversão na produção dirigida por Afonso Poyart. Cinema com Rapadura, 2012. Disponivel em: http://cinemacomrapadura.com.br/criticas/247172/2-coelhos-ousadia-e-diversao-naproducao-dirigida-por-afonso-poyart/. Acesso em: 29 out. 2017.

FINRA. The reality of investment risk. 2017. Disponivel em: http://www.finra.org/investors/reality-investment-risk. Acesso em: 02 out. 2017.

FORNAZARI, F. K. Instituições do Estado e políticas de regulação e incentivo ao cinema no Brasil: o caso Ancine e Ancinav. Revista de Administração Pública, v. 40, n.4, p. 658, 2006.

FSA. PRODECINE - Programa de Apoio ao Desenvolvimento do Cinema Brasileiro. Rio de Janeiro, 2017. Disponível em: https://fsa.ancine.gov.br/programas/prodecine. Acesso em: 26 set. 2017.

G1. Com 143 filmes, cinema brasileiro bate recorde de lançamentos em 2016. G1, Rio de Janeiro, 31 jan. 2017. Disponível em: https://g1.globo.com/poparte/cinema/noticia/com-143-filmes-cinema-brasileiro-bate-recorde-de-lancamentosem-2016.ghtml. Acesso em: 12 set. 2017.

HESSEL, R. Cenário desolador nas fábricas: queda na produção passa de $60 \%$. Correio Braziliense, 24 abr. 2017. Disponível em: http://www.correiobraziliense.c om.br/app/noticia/economia/2017/04/24/internas_economia,590501/quedanaproducao-passa-de-60-em-alguns-segmentos-industriais-no-pais.shtml. Acesso em: 13 set. 2017.

LAFUENTE, F.; ZANONI, L.; ALMEIDA, L. M. Red Bull, um estudo de caso de branded content. HSM Publishing, 15 fev. 2016. Disponível em: http://www.revistahsm.com.br/marketing-e-vendas/red-bull-um-estudo-de-caso-debranded-content/. Acesso em: 06 nov. 2017. 
MARKETWATCH. U.S. 10 YEAR Treasury Note. 2017. Disponível em: https://www.marketwatch.com/investing/bond/tmubmusd10y? countrycode=bx. Acesso em: 22 out. 2017.

MEIO\&MENSAGEM. Netflix: mais receita que SBT e mais assinantes que SKY. Meio\&Mensagem, Rio de Janeiro, 13 dez. 2016. Disponível em: http://www.meioemensagem.com.br. Acesso em: 28 set. 2017.

MELO, L. Os 10 filmes de maior bilheteria no Brasil em 2016 - até agora. EXAME, 29 dez. 2016. Disponível em: https://exame.abril.com.br/negocios/os-10-filmes-demaior-bilheteria-no-brasil-em-2016-ate-agora/. Acesso em: 14 set. 2017.

OCA. Mercado audiovisual brasileiro. Rio de Janeiro, 2017. Disponível em: https://oca.ancine.gov.br/mercado-audiovisual-brasileiro. Acesso em: 28 set. 2017.

OLHAR DIGITAL. Brasil é $4^{\circ}$ em lista de pirataria de filmes na internet. 23 jun. 2014. Disponivel em: https://olhardigital.com.br/noticia/brasil-e-4-em-lista-de-pirataria-defilmes-na-internet/42706. Acesso em: 02 out. 2017.

QUERO INCENTIVAR. Lei Rouanet. Rio de Janeiro, 2017. Disponível em: http://queroincentivar.com.br/leis-de-incentivo/lei-rouanet/. Acesso em: 26 set. 2017.

QUERO INCENTIVAR. Lei do Audiovisual. Rio de Janeiro, 2017. Disponível em: http://queroincentivar.com.br/leis-de-incentivo/lei-do-audiovisual/. Acesso em: 26 set. 2017.

REILLY, T.; CUNNINGHAM, T. 41 A-list actors who bombed. The Wrap, 28 jan. 2015. Disponível em: https://www.thewrap.com/41-a-list-actors-who-bombed-as-hard-asjohnny-depp-in-mordecai/ Acesso em: 02 out. 2017.

ROCHA, L. O shaolin do sertão atinge meio milhão de espectadores e supera público de Cine Holliúdy. Tribuna do Ceará, 15 nov. 2016. Disponível em: http://tribunadoceara.uol.com.br/diversao/cinema/o-shaolin-do-sertao-atinge-meio-milhao-deespectadores-e-supera-publico-de-cine-holliudy/. Acesso em: 05 nov. 2017.

RODRIGUES, C. 0 cinema e a produção. 2. ed. Rio de Janeiro: Lamparina, 2007. p. 68.

SALLES, F. Como se faz cinema. Mnemocine, 30 set. 2008. Disponível em: http://www.mnemocine.com.br/index.php/downloads/doc_download/3-apendice-2etapas-da-producao-cinematografica. Acesso em: 20 set. 2017. 
SEBRAE. O que são custos fixos e custos variáveis. Rio de Janeiro, 2016. Disponível em: https://www.sebrae.com.br/sites/PortalSebrae/ufs/ap/artigos/o-que-sao-custos-fixos-ecustosvariaveis,69cb1e2c6182c410VgnVCM1000003b74010aRCRD.

SNYDER, B. 7 insights from legendary investor Warren Buffet. CNBC, 01 maio 2017. Disponivel em: https://www.cnbc.com/2017/05/01/7-insights-from-legendary-investorwarren-buffett.html. Acesso em: 02 out. 2017.

STERNHEIM, A. O orçamento e o faturamento dos filmes nacionais. GGN, 07 nov. 2013. Disponível em: https://jornalggn.com.br/noticia/o-orcamento-e-o-faturamentodos-filmes-nacionais. Acesso em: 18 out. 2017.

ZAVERUCHA, V. Lei do Audiovisual: passo a passo. Rio de Janeiro, 1996. Disponível em: https://www.ancine.gov.br/sites/default/files/artigos/LEI_AUDIOVISUAL.pdf. Acesso em: 26 set. 2017. 